\title{
Post-cracking tensile behaviour of steel-fibre-reinforced roller-compacted-concrete for FE modelling and design purposes
}

\author{
N. Jafarifar ${ }^{\mathrm{a}} 凹$, K. Pilakoutas ${ }^{\mathrm{b}}, \mathrm{H}$. Angelakopoulos ${ }^{\mathrm{b}}$, T. Bennett ${ }^{\mathrm{c}}$ \\ a. School of Architecture and Built Environment, Robert Gordon University, (Aberdeen, UK) \\ b. Department of Civil and Structural Engineering, University of Sheffield, (Sheffield, UK) \\ c. School of Civil, Environmental and Mining Engineering, University of Adelaide, (Adelaide, Australia) \\ $\triangle$ n.jafarifar@rgu.ac.uk
}

\begin{abstract}
Fracture of steel-fibre-reinforced-concrete occurs mostly in the form of a smeared crack band undergoing progressive microcracking. For FE modelling and design purposes, this crack band could be characterised by a stress-strain $(\sigma-\varepsilon)$ relationship. For industrially-produced steel fibres, existing methodologies such as RILEM TC 162-TDF (2003) propose empirical equations to predict a trilinear $\sigma-\varepsilon$ relationship directly from bending test results. This paper evaluates the accuracy of these methodologies and their applicability for rollercompacted-concrete and concrete incorporating steel fibres recycled from post-consumer tyres. It is shown that the energy absorption capacity is generally overestimated by these methodologies, sometimes up to $60 \%$, for both conventional and roller-compacted concrete. Tensile behaviour of fibre-reinforced-concrete is estimated in this paper by inverse analysis of bending test results, examining a variety of concrete mixes and steel fibres. A multilinear relationship is proposed which largely eliminates the overestimation problem and can lead to safer designs.
\end{abstract}

KEYWORDS: Concrete; Composite; Fibre reinforcement; Metal reinforcement; Waste treatment

Citation/Citar como: Jafarifar, N.; Pilakoutas, K.; Angelakopoulos, H.; Bennett, T. (2017) Post-cracking tensile behaviour of steel-fibre-reinforced roller-compacted-concrete for FE modelling and design purposes Mater. Construcc. 67 [326], e122. http://dx.doi.org/10.3989/mc.2017.06716

RESUMEN: Comportamiento a tracción posterior a la fisuración del hormigón reforzado con fibras de acero compactado con rodillo para el diseño y modelado EF. La rotura del hormigón reforzado con fibra de acero se produce principalmente en forma de una banda de fisuración que sufre progresiva microfracturación. Para el diseño y modelado EF, esta banda se puede caracterizar por una relación tensión-deformación $(\sigma-\varepsilon)$. Para fibras de acero industriales, existen metodologías (RILEM TC 162-TDF 2003) que proponen ecuaciones empíricas para predecir una relación $\sigma-\varepsilon$ trilinear a partir de resultados de pruebas de flexión. En este artículo se evalúa la precisión de estas metodologías y su aplicación para hormigón compactado con rodillo y hormigón reforzado con fibras de acero recicladas provenientes de neumáticos usados. Se demuestra que estas metodologías generalmente sobreestiman la capacidad de absorción de (hasta un 60\%) tanto para el hormigón convencional como para el compactado con rodillo. En este artículo se calcula el comportamiento a tracción del hormigón reforzado con fibra mediante el análisis inverso de resultados de pruebas de flexión de varias composiciones de hormigón y fibras de acero. Se propone una relación multilinear que elimina en gran medida el problema de sobreestima, y puede conducir a diseños más seguros.

PALABRAS CLAVE: Hormigón; Composite; Refuerzo de fibras; Refuerzo metálico; Tratamiento de residuos

ORCID ID: N. Jafarifar (http://orcid.org/0000-0003-1988-2675); K. Pilakoutas (http://orcid.org/0000-0001-66727665); H. Angelakopoulos (http://orcid.org/0000-0001-5349-7311); T. Bennett (http://orcid.org/0000-0002-3979-769X)

Copyright: (C) 2017 CSIC. This is an open-access article distributed under the terms of the Creative Commons Attribution License (CC BY) Spain 3.0. 


\section{INTRODUCTION}

Steel fibre reinforced concrete (SFRC) is a composite material whose mechanical characteristics depend on the properties of the fibres and concrete, as well as the interface between fibres and matrix. Steel fibres enhance the post-cracking tensile behaviour of concrete and can increase the overall flexural toughness and load bearing capacity. To capitalise on the benefits of SFRC for structural applications, the post crack tensile characteristics of SFRC ( $\sigma-\varepsilon$ relationship) must be known for modelling and design purposes.

Currently, there is no accepted standard test methodology to determine SFRC properties in direct tension, as uniaxial tension tests on concrete are extremely difficult to perform (1). Fib Model Code 2010 (2) introduces a model for the constitutive law of SFRC in uniaxial tension using the residual flexural strength values. Fib model is based on the stress-crack opening $(\sigma-w)$ response as the main reference material property in the post-cracking range. The definition of a stress-strain $(\sigma-\varepsilon)$ law in uniaxial tension, using that code, requires the introduction of a structural characteristic length which represents a "bridge" to connect continuous mechanics. The characteristic length can be influenced by physical parameters such as maximum aggregate size, or element size in FE models. RILEM TC 162-TDF (3) proposes a methodology to predict the $\sigma-\varepsilon$ behaviour of SFRC, directly, as a trilinear model from flexural tests. The accuracy of that methodology has received criticism in a number of studies assessing the influence of different factors including fibre content, percentage of cement replaced by fly ash, SFRC age and the size-effect (4-7). However, RILEM $\sigma-\varepsilon$ model is still one of the most frequently used models for continuous mechanics. Barros et al. (5) show that by using the $\sigma-\varepsilon$ relationship proposed by RILEM TC 162-TDF (3) a higher initial residual force is predicted followed by a load decay which is not observed in the experiments. These authors then adjust the values of the recommended parameters by using inverse analysis on their own data, from a flexural test series, and a cross sectional layered model.

One novel application of SFRC is in road pavements, where the roller-compacted concrete (RCC) technology has been proposed for use with SFRC to reduce the construction time (8). The use of recycled-tyre-steel-fibres (RF), as an environmentally friendly alternative to the industrially produced steel fibres (IF), has also been demonstrated and patented by the University of Sheffield $(9,10)$. An EU funded research project, Ecolanes (11), developed optimised processes for roller-compacted SFRC utilising RF for road pavements. This application was also extensively investigated for long term performance and shrinkage (12-15). In this paper, both RCC and conventional concrete (CC) reinforced with IF and RF are examined as possible SFRC compositions for future applications. For cross checking purposes, both section analysis and FE method are adopted to obtain the $\sigma-\varepsilon$ constitutive law for the tested mixes using inverse analysis.

The trilinear empirical $\sigma-\varepsilon$ constitutive law of SFRC suggested by RILEM TC 162-TDF (3) and Barros et al. (5) have been originally calibrated for conventional concrete incorporating industrial fibres. The accuracy of these estimations for conventional SFRC is assessed in this paper, as well as their applicability for steel-fibre-reinforced rollercompacted-concrete (SFR-RCC) and concrete incorporating irregular-shape recycled steel fibres. A multilinear $\sigma-\varepsilon$ relationship is proposed based on the performed numerical and experimental studies. This relationship can predict the post-cracking behaviour of SFRC when incorporating recycled steel fibres or when RCC technology is used for casting concrete.

The paper begins by reviewing the empirical estimations proposed by RILEM TC 162-TDF (3) and the adjustments suggested by Barros et al. (5). Bending test results from a variety of SFRC mixes are then presented, followed by discussing the methods used for numerical inverse analysis and the results.

\section{EMPIRICAL ESTIMATIONS OF THE $\sigma$ - $\varepsilon$ CONSTITUTIVE LAW}

Figure 1 shows the trilinear $\sigma-\varepsilon$ diagram suggested by RILEM TC 162-TDF (3) to model tension stiffening behaviour of SFRC. This diagram is defined by the following empirically calibrated relations [1]:

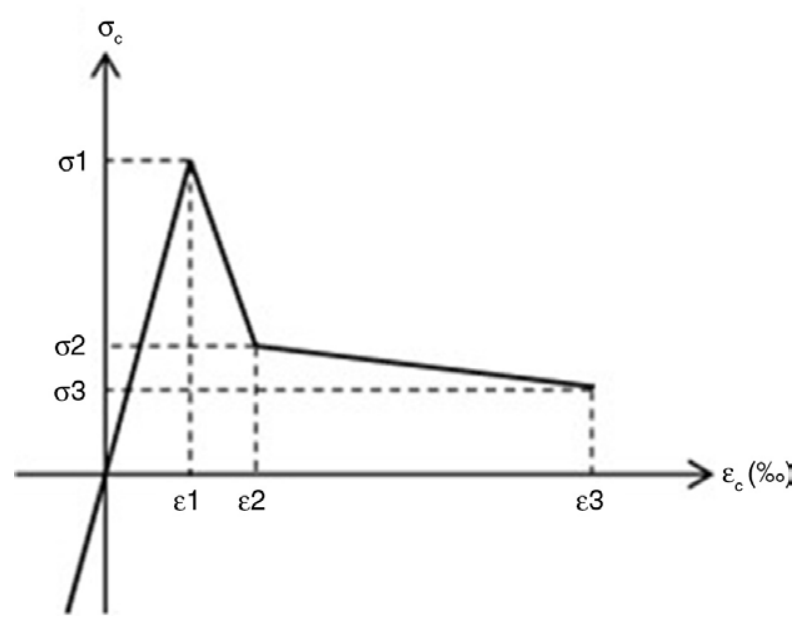

FIGURE 1. Trilinear $\sigma$ - $\varepsilon$ diagram for SFRC, according to RILEM TC 162-TDF (2003). 


$$
\begin{array}{rrrl}
\sigma_{1}=0.7 f_{c t m, f l}(1.6-d) ; & \sigma_{2}=0.45 f_{R, 1} k_{h} ; & \sigma_{3}=0.37 f_{R, 4} k_{h} \\
\varepsilon_{1}=\sigma_{1} / E_{c} ; & \varepsilon_{2}=\varepsilon_{1}+0.1 \% 0 & \varepsilon_{3}=25 \% 0 \\
k_{h}=1.0 & \text { for } \quad h<125 \mathrm{~mm} \\
k_{h}=-0.001263 h+1.1579 & \text { for } \quad 125 \mathrm{~mm} \leq h \leq 600 \mathrm{~mm} \\
k_{h}=0.4 & \text { for } \quad 600 \mathrm{~mm}<h
\end{array}
$$

Where, $f_{c t m, f l}$ and $E_{c}$ are the average flexural tensile strength and Young's modulus, respectively (in $\mathrm{MPa}$ ); $d$ is the effective beam depth (in $\mathrm{m}$ ); $k_{h}$ is the size factor representing the effect of the cross section height, $h$; and $f_{R, 1}$ and $f_{R, 4}$ are residual flexural strength parameters obtained from the bending load-deflection results (3).

Barros et al. (5) observed a lack of precision when using the $\sigma-\varepsilon$ model proposed by RILEM TC $162-\mathrm{TDF}$ (3) in numerical regeneration of the load versus deflection $(P-\delta)$ relationship for a series of flexural tests. That study showed that by using the $\sigma-\varepsilon$ law proposed by RILEM, there is a tendency to predict a higher residual force up to a deflection of about $1.8 \mathrm{~mm}$, followed by a load decay which was not observed in the experiments (see Figure 2). This was attributed to the stress transfer loss of the layers exceeding strain $\varepsilon_{3}$, shown in Figure 1. Barros et al. (5) tried to adjust the values of the recommended parameters performing an inverse analysis with an optimisation procedure. A cross section layered model was used for beams comprising of two blocks, behaving in a linear elastic fashion, connected by a non-linear hinge of length, s, where the main nonlinear behaviour due to cracking is concentrated (s was considered equal to half of the net height of the fracture surface according to RILEM TC 162TDF (16). New relations were given as follows. It should be noted that the standard deviations of the calibrated results are very high for $\varepsilon_{2}$ and $\varepsilon_{3}$ [2].

$$
\begin{array}{lll}
\sigma_{1}=0.52 f_{c t m, f l}(1.6-\mathrm{d}) ; & \sigma_{2}=0.36 f_{R, 1} k_{h} ; & \sigma_{3}=0.27 f_{R, 4} k_{h} \\
\mathcal{E}_{1}=\sigma_{1} / E_{c} ; & \mathcal{E}_{2}=1.2 \% 0(\mathrm{SD} 0.5) ; & \mathcal{E}_{3}=104 \% 0(\mathrm{SD} 26)
\end{array}
$$

The results of the following experimental study are used to assess both RILEM TC 162-TDF (3) and Barros et al. (5) methodologies in predicting $\sigma-\varepsilon$ behaviour of SFRC, particularly when recycled steel fibres or RCC technology is used.

\section{EXPERIMENTAL STUDIES}

\subsection{Materials and compositions}

Eight SFRC and two plain mixes were cast including both RCC and $\mathrm{CC}$. The aggregates used for $\mathrm{CC}$ mixes were river aggregates, whilst graded crushed granite (typical of the UK practice) was used for the RCC mixes to increase the bond between the paste and aggregate and to provide stability during rolling. The nominal maximum size of coarse aggregates was limited to $14 \mathrm{~mm}$ for RCC and to $10 \mathrm{~mm}$ for $\mathrm{CC}$; the gradation of the aggregates is given in Jafarifar et al. (14). The mix proportions used, typical of UK practice, is shown in Table 1. A sulfoaluminate low energy cement was adopted to reduce environmental impact. Recommendations of the BS 8500-1 (17) were used for CC to develop a designated mix that can be used for heavy-duty external paving. Considering cyclic wet and dry conditions with an intended working life of at least 50 years, a cement content of $380 \mathrm{~kg} / \mathrm{m} 3$ and a water-cement ratio of 0.35 were required.

For the RCC mix design, the cement content of $300 \mathrm{~kg}$ was needed to achieve the same strength as for CC. The water content for RCC was chosen to yield the maximum dry density of the compacted

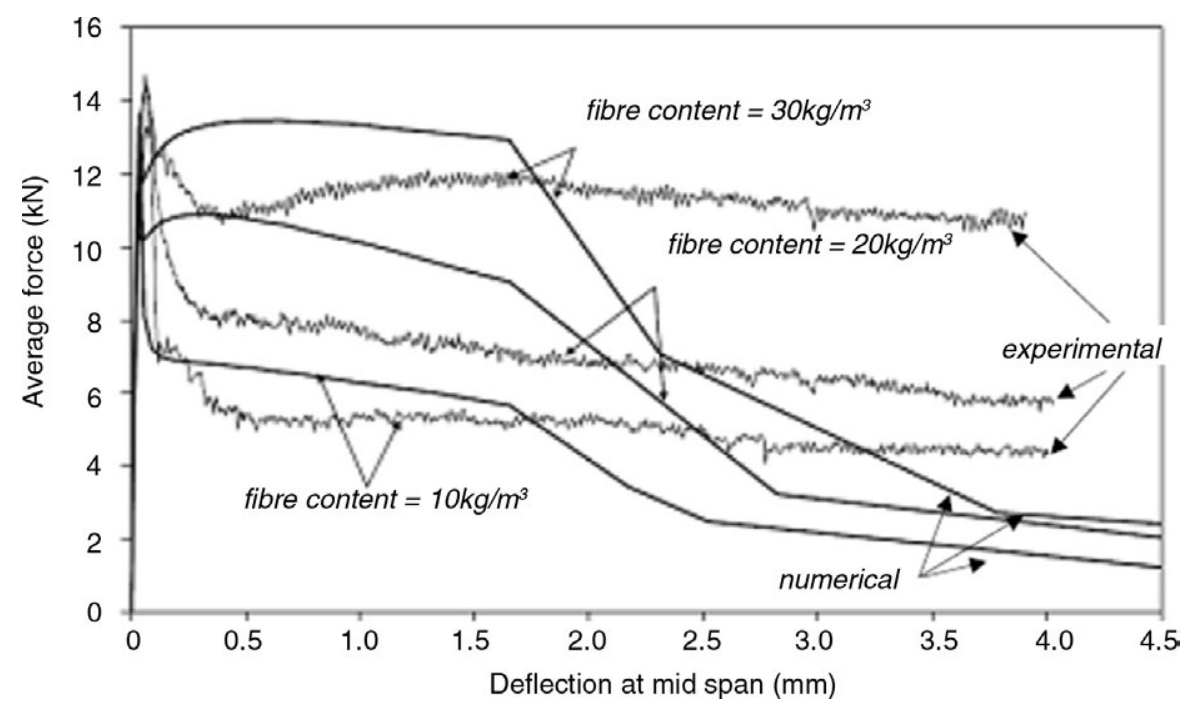

FIgURE 2. Comparison made by Barros et al. (2005) between experimental and numerical P- $\delta$ curves when using the $\sigma-\varepsilon$ law proposed by RILEM TC 162-TDF (2003) in their numerical model. 
TABLE 1. Proportions used for concrete mixes

\begin{tabular}{lccccccc}
\hline Mix & Cement $\left(\mathbf{k g} / \mathbf{m}^{3}\right)$ & W/C & $\begin{array}{c}\text { Crushed aggreg. } \\
\left(\mathbf{k g} / \mathbf{m}^{\mathbf{3}}\right)\end{array}$ & $\begin{array}{c}\text { River aggreg. } \\
\left(\mathbf{k g} / \mathbf{m}^{\mathbf{3}}\right)\end{array}$ & $\begin{array}{c}\text { Sand } \\
\left(\mathbf{k g} / \mathbf{m}^{3}\right)\end{array}$ & Superplasticizer $^{\mathbf{a}}$ & Air-entrainer $^{\mathbf{a}}$ \\
\hline CC & 380 & 0.35 & - & 1004 & 833 & $0.85 \%$ & $0.135 \%$ \\
RCC & 300 & 0.54 & 2084 & - & - & - & - \\
\hline
\end{tabular}

a $\%$ by cement mass.

mix; $7 \%$ for the used cement and aggregates. For CC mixes, the target slump was $70 \mathrm{~mm}$.

Three different fibre types were used: one RF, and two IF. The recycled fibres from tyres used in this study had diameters in the range of 0.1 to $0.23 \mathrm{~mm}$ and a tensile strength of around $2000 \mathrm{MPa}$. These fibres have irregular shapes and lengths, so their length distribution is determined using optical measurements (8). In this study, $85 \%$ of the fibres had length in the range of 10 to $25 \mathrm{~mm}$, and $50 \%$ of them in the range of 15-25 mm. Details of statistical length distribution can be found in Jafarifar et al. (14). Ecolanes (11) determined the optimum practical amount of recycled fibres in the range of $50-60 \mathrm{~kg}$ per cubic meter of concrete (or around $2-2.5 \%$ by mass). However, higher percentage of recycled fibres $(4 \%$ and $6 \%$ by mass) and plain concrete mixes were also examined. For IF, $2 \%$ of fibres by mass of concrete is commonly used for suspended slabs. Two types of industrial fibres were examined: twincone (diameter 1mm, length $54 \mathrm{~mm}$ ) and hooked-end (diameter $1 \mathrm{~mm}$, length $50 \mathrm{~mm}$ ), all with the same nominal tensile strength (1100 MPa).

To compact RCC specimens in the laboratory, a purpose made apparatus having a fixed weight and a $1.6 \mathrm{~kW}$ electric vibrating hammer (16 to $32.5 \mathrm{~Hz})$ was used (8). RCC specimens were cast in three layers (five layers for cylinders) each compacted for 60 seconds.

\subsection{Bending tests}

Flexural prisms are commonly tested under three or four point loading. For SFRC, the difference between the two tests (three or four-point bending test) is not so large when a careful non-linear computation is carried out (18). RILEM proposes a three-point bending test, but in this study a fourpoint load arrangement was adopted as it creates a region of constant moment at the middle of the prism and minimises the load-spreading effect at the point of load application (19).

Most standards $(3,20-22)$ require a notch at the middle of the prism in order to concentrate cracking at a predefined section, whereas some others (23, $24)$ do not require a notch. In an un-notched prism, cracking may form at any section in the middle onethird of the length, where the moment is maximum and constant. When the test aims to study fracture energy of concrete through load versus crack mouth opening, it is more appropriate to follow the notched-prism testing procedure. To obtain the bending moment versus curvature (or to obtain $\sigma-\varepsilon$ curve), un-notched prism testing can also be used. In this study both notched and un-notched prism tests were undertaken for comparison purposes.

Three $150 \times 150 \times 550 \mathrm{~mm}$ prisms (per mix) were cast in steel-plate moulds, following the recommendations of BS EN 14651 (20). Notches were cut ( $25 \mathrm{~mm}$ height and $5 \mathrm{~mm}$ width) on the tensile side of the specimens at mid-span, using a rotating diamond blade. For RCC specimens the notch was perpendicular to the compacted layers and for $\mathrm{CC}$ it was on a side at $90^{\circ}$ to the casting direction.

The specimens were tested under displacement control in a $1000 \mathrm{kN}$ servo-hydraulic machine. To exclude torsional effects and to measure the net deflection at the mid-span (in relation to the neutral axis of the beam at its support), a yoke was used as specified by JSCE-SF4 (21). For the notched prisms, the rate of displacement was controlled by the crack mouth opening, while for the un-notched prisms it was controlled by the mid-span deflection using two transducers fixed to the yoke on both sides.

The mean compressive strength of the mixes was obtained from three cylinders $150 \times 300 \mathrm{~mm}$ (per mix) based on BS EN 12390-3 (25). The specimen codes and a summary of characteristics of the mixes and specimens are given in Table 2, including the age of testing, mean compressive strength, mean bending $\mathrm{E}$ modulus, and the standard deviations. The mean bending elastic modulus has been obtained from bending test results from three specimens per mix and based on the formula derived by Alexander (26). Mid-span beam deflections versus applied loads are presented and discussed in Section 5.

\section{NUMERICAL INVERSE ANALYSIS; METHODS AND ISSUES}

The $\sigma-\varepsilon$ relationship in tension is essential for SFRC numerical modelling. This relationship is not easy to determine directly in tension, and is best obtained by coupling experimental (flexural tests) and numerical techniques (inverse analysis). In this paper for cross checking purposes, section analysis and the FE method are used for inverse analysis of the bending test results. This is to avoid any unexpected potential source of inaccuracy in the numerical studies. 
TABLE 2. Experimental SFRC and plain specimens

\begin{tabular}{|c|c|c|c|c|c|c|c|c|}
\hline \multirow[b]{2}{*}{ Specimen code } & \multirow[b]{2}{*}{ Consistency } & \multirow{2}{*}{$\begin{array}{l}\text { Cement } \\
\text { content } \\
\left(\mathrm{kg} / \mathrm{m}^{3}\right)\end{array}$} & \multicolumn{2}{|c|}{ Fibre } & \multirow{2}{*}{$\begin{array}{l}\text { Prism } \\
\text { Notched or } \\
\text { Unnotched }\end{array}$} & \multirow{2}{*}{$\begin{array}{c}\text { Mean } \\
\text { compressive } \\
\text { strength (SD) } \\
\text { (cylinders, MPa) }\end{array}$} & \multirow{2}{*}{$\begin{array}{c}\text { Mean } \\
\text { bending E } \\
\text { modulus } \\
\text { (SD) }(\mathrm{GPa})\end{array}$} & \multirow{2}{*}{$\begin{array}{l}\text { Age of } \\
\text { tests, } \\
\text { days }\end{array}$} \\
\hline & & & Type & Content* & & & & \\
\hline CC-C380-0-90d-N & $\mathrm{CC}$ & 380 & - & 0 & Notched & $56(0.5)$ & $42.5(3.1)$ & 90 \\
\hline CC-C380-0-90d-UN & $\mathrm{CC}$ & 380 & - & 0 & Unnotched & $56(0.5)$ & $42.5(3.1)$ & 90 \\
\hline CC-C380-IH2-28d-N & $\mathrm{CC}$ & 380 & Hooked & $2 \%$ & Notched & $50(1.6)$ & $48.0(2.1)$ & 28 \\
\hline CC-C380-IT2-28d-N & $\mathrm{CC}$ & 380 & Twincone & $2 \%$ & Notched & $52(2.0)$ & $48.0(1.4)$ & 28 \\
\hline CC-C380-R2-90d-N & $\mathrm{CC}$ & 380 & Recycled & $2 \%$ & Notched & $61(4.8)$ & $43.1(2.7)$ & 90 \\
\hline CC-C380-R2-90d-UN & $\mathrm{CC}$ & 380 & Recycled & $2 \%$ & Unnotched & $61(4.8)$ & $43.1(2.7)$ & 90 \\
\hline RCC-C300-0-90d-N & RCC & 300 & - & 0 & Notched & $50(0.5)$ & $41.9(0.7)$ & 90 \\
\hline RCC-C300-0-90d-UN & $\mathrm{RCC}$ & 300 & - & 0 & Unnotched & $50(0.5)$ & $41.9(0.7)$ & 90 \\
\hline RCC-C300-IH2-28d-N & $\mathrm{RCC}$ & 300 & Hooked & $2 \%$ & Notched & $28(1.2)$ & $30.0(0.9)$ & 28 \\
\hline RCC-C300-IT2-28d-N & RCC & 300 & Twincone & $2 \%$ & Notched & $33(0.4)$ & $32.0(0.5)$ & 28 \\
\hline RCC-C300-R2-90d-N & RCC & 300 & Recycled & $2 \%$ & Notched & $56(3.9)$ & $41.0(1.6)$ & 90 \\
\hline RCC-C300-R2-90d-UN & $\mathrm{RCC}$ & 300 & Recycled & $2 \%$ & Unnotched & $56(3.9)$ & $41.0(1.6)$ & 90 \\
\hline RCC-C300-R4-28d-N & RCC & 300 & Recycled & $4 \%$ & Notched & $38(3.2)$ & $34.5(0.2)$ & 28 \\
\hline RCC-C300-R6-28d-N & RCC & 300 & Recycled & $6 \%$ & Notched & $38(2.7)$ & $35.5(0.6)$ & 28 \\
\hline
\end{tabular}

* by mass of concrete.

\subsection{Section analysis}

Sectional inverse analysis is an iterative procedure to calculate the stress distribution through an individual cross-section. The key assumption is that plane sections remain plane. The load is increased gradually; the neutral axis depth and the stress distribution through the mid span are calculated at each step based on force equilibrium (4). The post-cracking $\sigma-\varepsilon$ relationship is incrementally determined; for that, the moment versus curvature of the section is transformed into load versus mid span deflection (27). The path of the $\sigma-\varepsilon$ curve is iteratively chosen so that the numerical load versus deflection $(P-\delta)$ curve matches the experimental one and the error function is minimised.

\subsection{The FE method}

The FE method can also be used for inverse analysis. Cracking can be described in two ways; discrete cracking and smeared cracking. The discrete crack model uses stress-crack opening $(\sigma-w)$ relationship as the softening law. The $\operatorname{crack}(\mathrm{s})$ location is predefined using cohesive elements. This approach is computationally expensive (4) and is not useful when crack location(s) may vary. In the other approach, it is assumed that cracking is smeared over a characteristic length and the stress-strain $(\sigma-\varepsilon)$ relationship is used to describe the softening law. The characteristic length in an FE model depends on element geometry and formulation (e.g. equal to the average element length for a first-order element). In this paper, the smeared crack approach is used to study the softening behaviour of SFRC mixes following a mesh sensitivity analysis.

\subsubsection{Material models (CSC versus CDP)}

The finite element package ABAQUS (28) is used for this study, in which the smeared crack approach can be adopted via two models namely "Concrete Smeared Crack" (CSC), and "Concrete Damaged Plasticity" (CDP). In CSC, representation of anisotropic behaviour of cracking dominates modelling, while CDP uses the concept of isotropic damage in combination with tensile and compressive plasticity to define the inelastic behaviour of concrete. Hence, the crack opening smeared over the element length in CSC is analogous to the inelastic deformation over the element length in CDP.

CSC, although able to model orthotropic damage, is prone to a virtual numerical stiffening and consequent instabilities in multi cracked conditions. This virtual stiffening happens when a fixed crack formulation is used, in which the crack orientation coincides with the orientation of the maximum principal stress at crack initiation and remains fixed throughout the loading time, while the orientation of principal stresses can change (29). CDP is expected to produce more stable solutions, although damage is applied isotropically. In this paper, both CSC and CDP models are examined to ensure that the above mentioned limitations do not affect the accuracy of the results. The required parameters to adopt these models are given in Table 3. 
TABLE 3. Required parameters for using CSC and CDP models in ABAQUS

\begin{tabular}{|c|c|c|c|c|}
\hline Constitutive model & \multicolumn{3}{|c|}{ Required parameter } & Determined/ Specified \\
\hline \multirow[t]{7}{*}{$\mathrm{CSC}$} & \multicolumn{3}{|l|}{ Uniaxial tension } & Experimentally \\
\hline & \multicolumn{3}{|l|}{ Uniaxial compression } & Experimentally \\
\hline & \multirow{4}{*}{\multicolumn{2}{|c|}{ Multi-axial failure ratios, as defined in ABAQUS (2010) }} & FR1 & A typical value (modified for SFRC; 1.2 ) \\
\hline & & & FR2 & Experimentally \\
\hline & & & FR3 & A typical value of 1.28 \\
\hline & & & FR4 & A typical value of 0.33 \\
\hline & \multicolumn{3}{|l|}{ Shear retention factors } & Full shear retention \\
\hline \multirow[t]{8}{*}{ CDP } & \multicolumn{3}{|l|}{ Uniaxial tension } & Experimentally \\
\hline & \multicolumn{3}{|l|}{ Uniaxial compression } & Experimentally \\
\hline & \multicolumn{3}{|c|}{ Damage factors in tension, as defined in ABAQUS (2010) } & Applied in the same rate as strain softening \\
\hline & \multicolumn{3}{|c|}{ Damage factors in compression*, as defined in ABAQUS (2010) } & Ignored \\
\hline & \multirow{4}{*}{$\begin{array}{l}\text { Multi-axial yield and } \\
\text { flow parameters }\end{array}$} & \multicolumn{2}{|l|}{ Dilation angle, $\psi$} & The best value from literature $\left(31^{\circ}\right)$ \\
\hline & & \multicolumn{2}{|l|}{ Eccentricity, $\varepsilon$} & A typical value of 0.1 \\
\hline & & \multicolumn{2}{|l|}{ FR1 } & A typical value (modified for SFRC; 1.2 ) \\
\hline & & \multicolumn{2}{|c|}{$K_{c}$ ratio, as defined in ABAQUS (2010) } & A typical value of $2 / 3$ \\
\hline
\end{tabular}

* Compressive damage is applicable for compressive strain-softening regime, which will never be reached herein since the compressive stresses are not dominant.

\subsubsection{Element type}

Shell elements are used to model flexural prisms, thus the model is computationally less expensive than when solid elements are used in several layers through the thickness. To model progressive failure of concrete with a good accuracy, at least nine integration points are required through the thickness of shell elements (28).

\section{RESULTS AND DISCUSSION}

Inverse analysis of the average experimental $P-\delta$ results was undertaken via three different numerical approaches (section analysis, FE analysis using CSC and CDP), to assess the reliability of the numerical results. This section presents and compares the results of the numerical approaches, discusses crack band-width and the mesh sensitivity issue and presents the results for both notched and un-notched prisms of RCC and CC. Finally, it discusses the accuracy of the empirical methods given in Section 2 and proposes a modified multilinear $\sigma-\varepsilon$ relationship.

\subsection{Crack band width, mesh sensitivity and comparison of the numerical approaches}

Mesh sensitivity results are presented for a typical RSFRC and a plain mix, for three selected element sizes $(25 \mathrm{~mm}, 37.5 \mathrm{~mm}$, and $75 \mathrm{~mm})$. The tensile multilinear s-erelationships used in the analysis were back-calculated from section analysis to obtain the best fit to the experimental average $P-\delta$ curves;

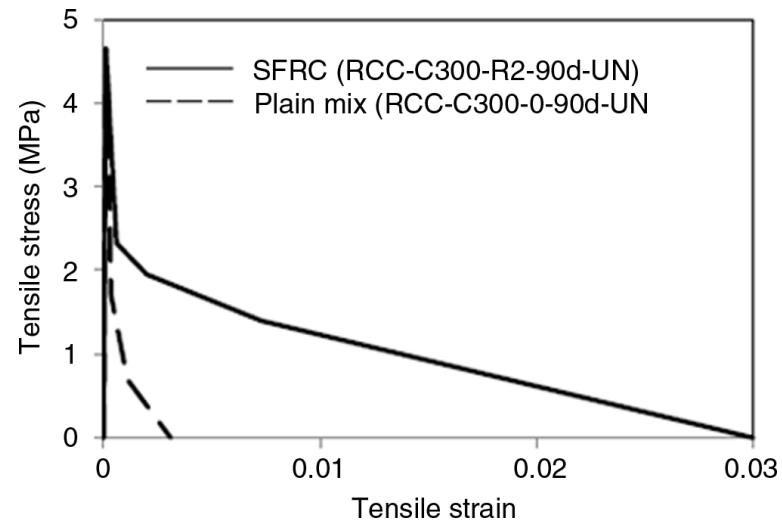

FIGURE 3. Back-calculated multilinear $\sigma-\varepsilon$ diagrams for typical mixes.

these are shown in Figure 3. The $P-\delta$ curves obtained by the FE method and section analysis are shown in Figure 4 and Figure 5 for plain mixes and RSFRC, respectively.

As shown for plain concrete in Figure 4(a) and 4(b), there is clear evidence of mesh sensitivity for the element size bigger that $37.5 \mathrm{~mm}$ for both FE approaches. The results obtained for $37.5 \mathrm{~mm}$ and $25 \mathrm{~mm}$ element sizes match well and this means that refinement to smaller than $37.5 \mathrm{~mm}$ does not lead to a narrower crack band. Thus, it can be concluded that a crack band width bigger than $75 \mathrm{~mm}(2 \times 37.5 \mathrm{~mm})$ is formed in the middle as the boundary of the strain-softening region (or the fracture process zone). For the $75 \mathrm{~mm}$ element size, a softer behaviour is predicted, as the fracture 
(a)

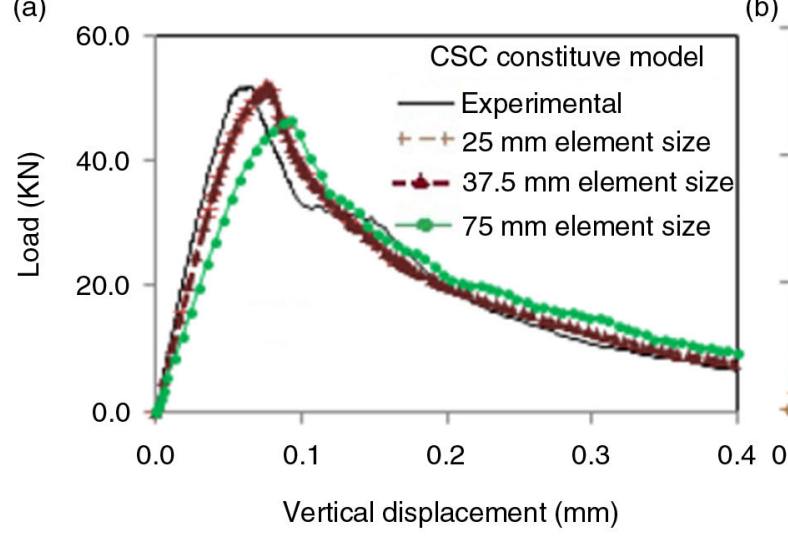

(b)

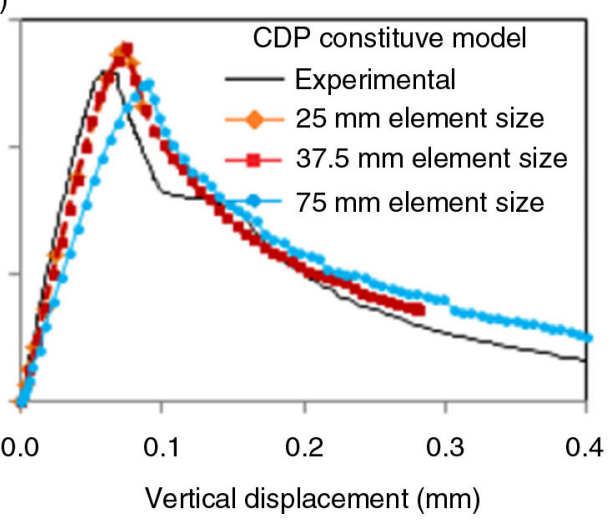

(c)

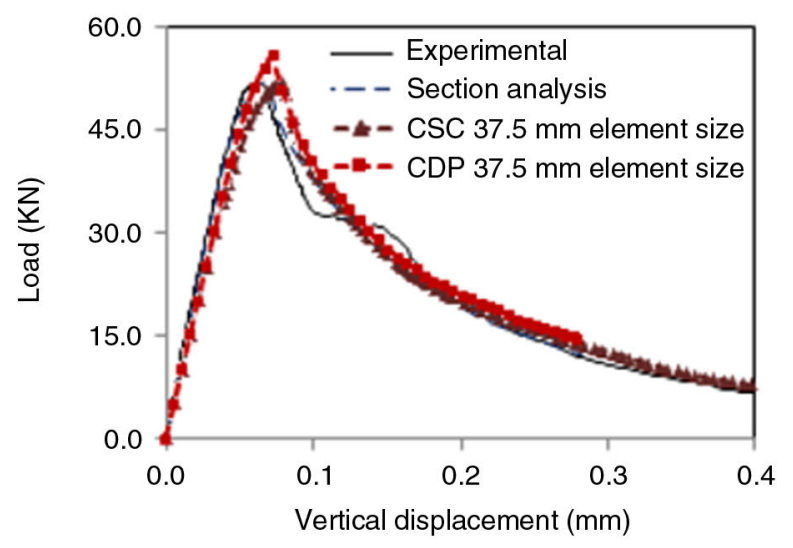

FIGURE 4. P- $\delta$ curves for a typical plain-mix prism (RCC-C300-0-90d-UN); (a) mesh sensitivity in CSC; (b) mesh sensitivity in CDP; (c) all numerical and experimental P- $\delta$ curves.

energy is distributed further along the element resulting in a crack band-width wider than in the experiments.

For the RSFRC mixes, as shown in Figure 5(a) and $5(\mathrm{~b})$, the results obtained for $75 \mathrm{~mm}$ element size are just slightly softer than the other sizes, showing that mesh refinement cannot considerably reduce the crack band width to less than $150 \mathrm{~mm}$ $(2 \times 75 \mathrm{~mm})$. Hence, for the RSFRC, the fracture process zone covers a high percentage of the constant-moment zone $(\approx 150 \mathrm{~mm})$.

This mesh sensitivity analysis shows that $37.5 \mathrm{~mm}$ first order elements are appropriate for the examined mixes. The obtained widths of the fracture process zone for these mixes ( $>75 \mathrm{~mm}$ for plain concrete and $\approx 150 \mathrm{~mm}$ for RSFRC) also comply well with the range predicted by Bazant and Oh (30) (2-6 times the average element dimension or the characteristic length), for a full development of the fracture process zone independent of the size effect. The size effect may arise from heterogeneity of concrete containing aggregates which are not necessarily small compared to the structural dimensions. Bazant an Oh (30) found that, for the optimum results, the ratio of the characteristic length to the aggregate size ranges from 1.5 to 4 , and suggested limiting the minimum value of this ratio to around 3 . This ratio is also respected by choosing $37.5 \mathrm{~mm}$ element size in this study (the average element length/ the maximum aggregate size $\approx 3$ ).

As shown in Figure 4(c) and Figure 5(c), since the $\sigma-\varepsilon$ relationship was determined from section analysis, as expected, the predictions shown for section analysis match extensively well the experimental results. Reasonable agreement is also reached between the three numerical approaches (section analysis, CSC and CDP), when an element size comparable to the fracture process zone is selected in the FE models (37.5 $\mathrm{mm}$ or smaller).

\subsection{Notched and un-notched prisms}

To examine its objectivity, the $\sigma-\varepsilon$ obtained for the un-notched prisms is used for section analysis of the notched prisms. The experimental $P-\delta$ curves for the notched and un-notched prisms are shown in Figure 6, for two typical SFRC mixes of RCC and $\mathrm{CC}$. It is seen that the existence of a notch significantly decreases the peak load, due to the reduced section at the mid-span.

The reduced height (i.e. the height at the midspan) is applied in the equations given by Casanova 

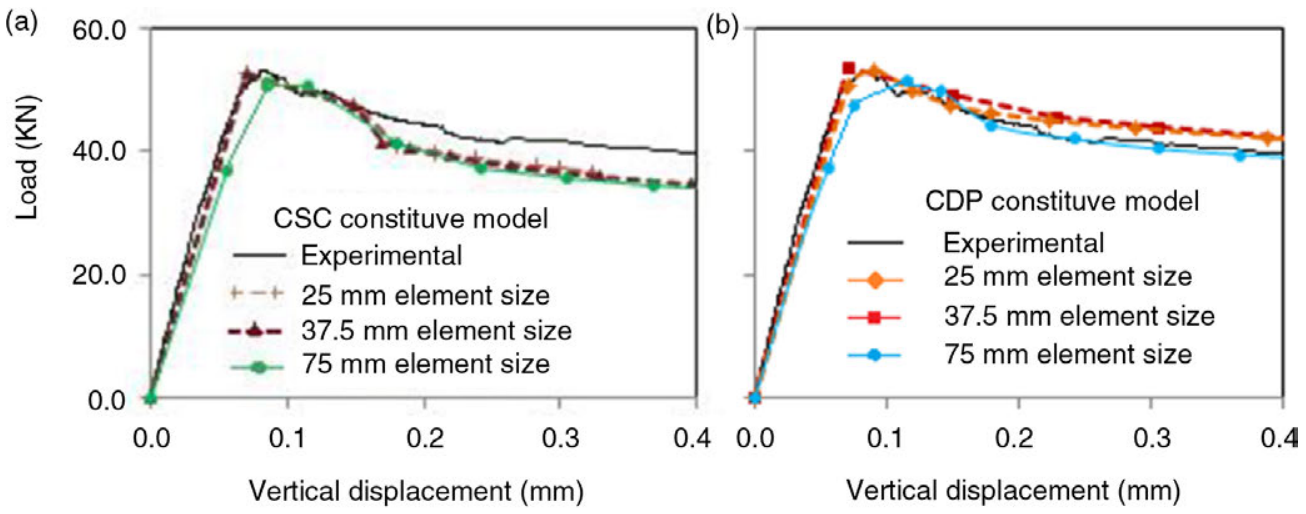

(c)

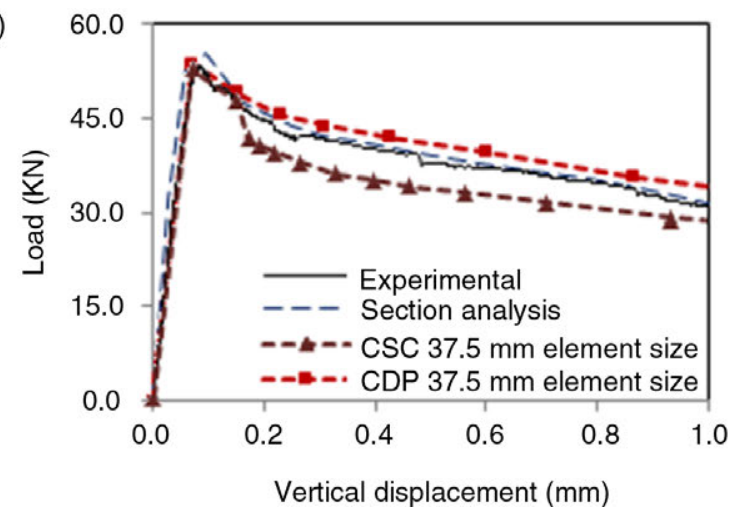

FIGURE 5. $P-\delta$ curves for a typical RSFRC prism (RCC-C300-R2-90d-UN); (a) mesh sensitivity in CSC; (b) mesh sensitivity in CDP; (c) all numerical and experimental $\mathrm{P}-\delta$ curves.

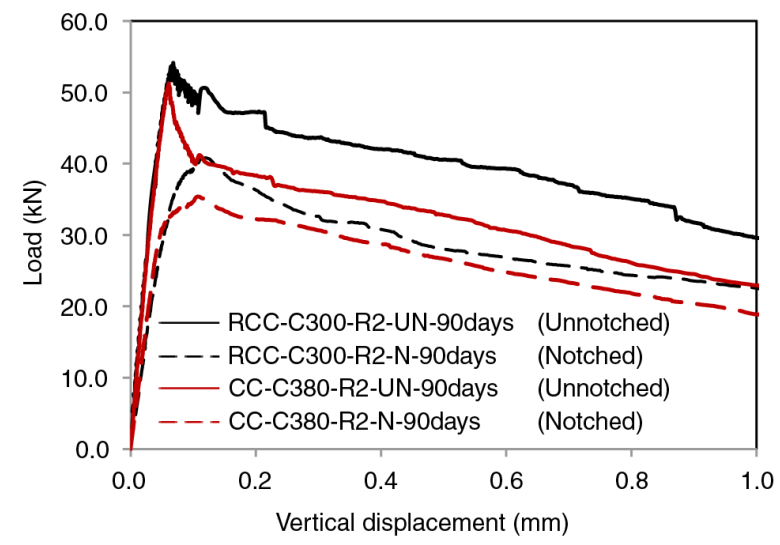

FIGURE 6. Effect of notch in decreasing the peak load in the experimental $\mathrm{P}-\delta$ curves.

and Rossi (27) to calculate load versus deflection $(P-\delta)$ for the moment-curvature obtained from section analysis. Using the $\sigma-\varepsilon$ obtained for the un-notched prisms, the predicted $P-\delta$ curve fits the experimental results of the notched prisms, as shown Figure 7(a) and 7(b) for RCC and CC mixes, respectively. This shows: 1) the stiffness of the notched prism can be approximated satisfactorily equal to the stiffness of an un-notched one with the same height as its mid-span; 2) the location and distribution of cracks through the constant-moment zone of the un-notched prisms did not distinguishably affect the results.

\subsection{Accuracy of the empirical methods (RILEM TC 162-TDF (2003) and Barros et al. (2005)) and their applicability for RSFRC}

To assess the accuracy of the empirical methods given by RILEM TC 162-TDF (3) and Barros et al. (5), numerical sectional inverse analysis is used for a variety of SFRC prisms (incorporating IF and RF) given in Table 2 . The obtained $\sigma-\varepsilon$ results from the empirical methods are compared with the predictions obtained from the numerical inverse analysis. Using section analysis, the predictions of the empirical methods are compared with the experimental results to evaluate the effect of any $\sigma-\varepsilon$ inaccuracies on the predicted energy absorption. Energy absorption is represented by the area under the $P-\delta$ curves by up to $3.0 \mathrm{~mm}$ mid-span deflection. The results for one SFRC mix (CC-C380-IT2-28d-N) and one RSFRC mix (RCC-C300-R2-90d-N) are presented in Figures 8 and 9, respectively. In these figures the $\sigma-\varepsilon$ predictions, the tensile strengths and the regenerated $P-\delta$ curves are shown for the 

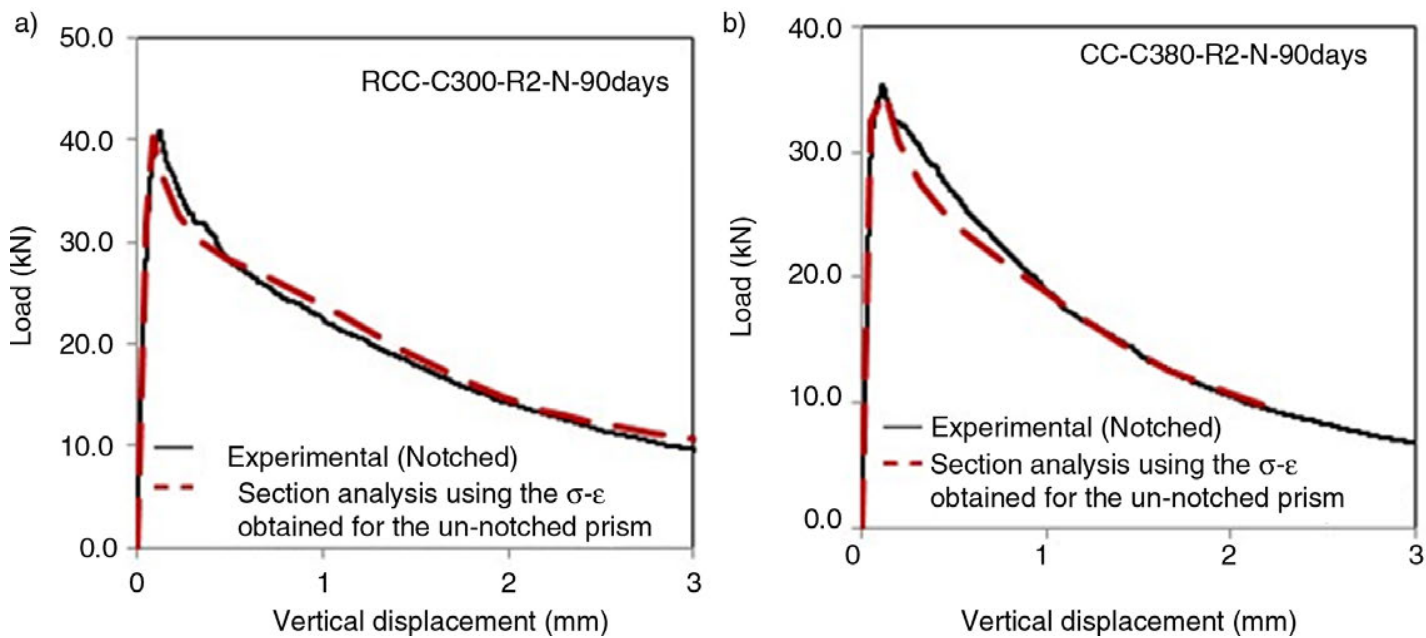

FIGURE 7. Numerically predicted P- $\delta$ for notched prisms compared to the experimental results; (a) RCC-C300-R2-N-90days; (b) CC-C380-R2-N-90days.
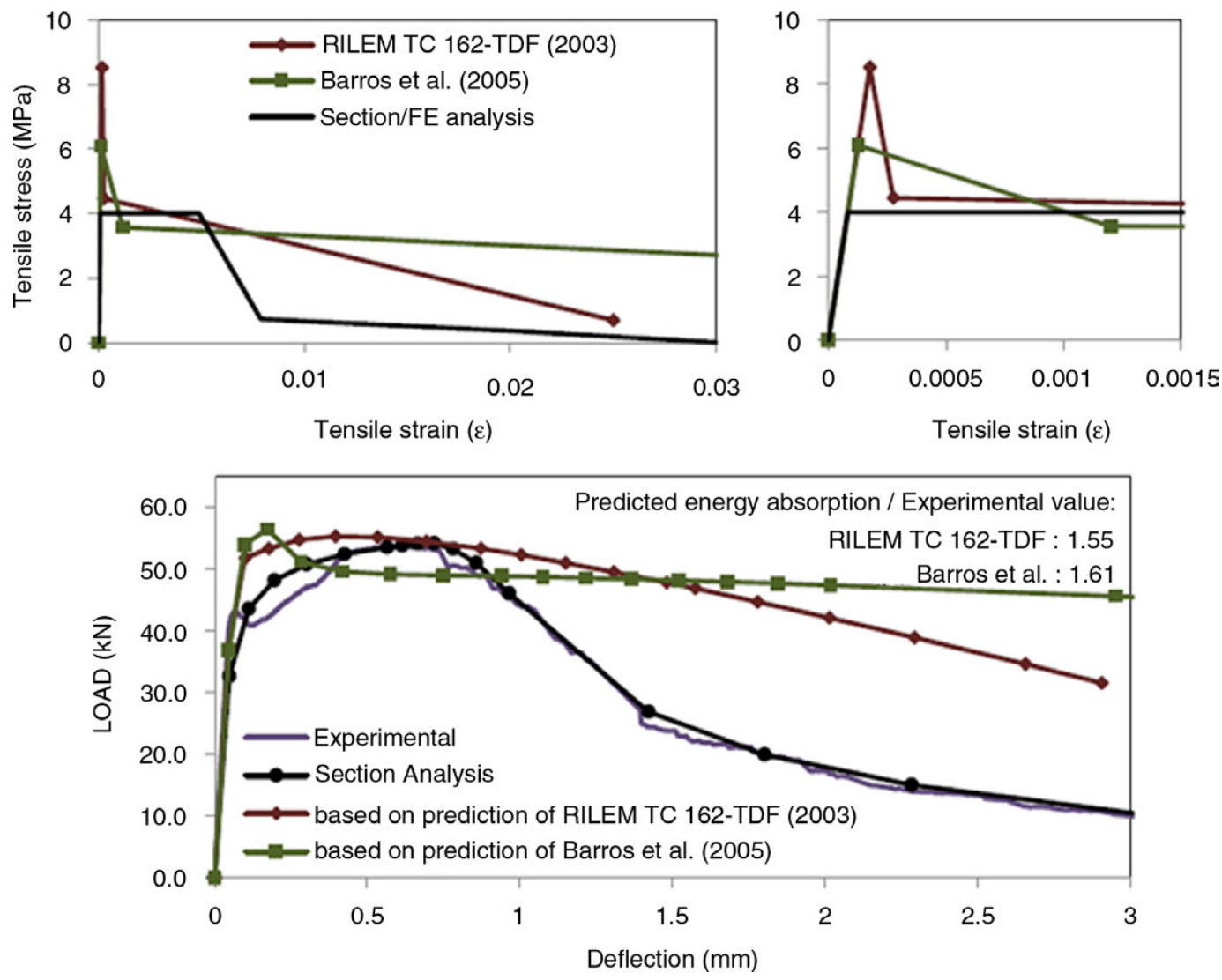

FIGURE 8. SFRC mix (CC-C380-IT2-28d-N); empirical trilinear estimations compared with section analysis.

existing empirical methods as well as for the numerical inverse analysis. From these figures the following data can be obtained:

- The overestimation in the predicted energy absorption (over the experimental value) for SFRC and RSFRC mixes,
- The predicted tensile strength (normalized to the predicted value by section analysis) for SFRC and RSFRC mixes,

- The total strain in the softening regime (extrapolated to reach zero stress and normalized to the predicted value by section analysis) for SFRC and RSFRC mixes 

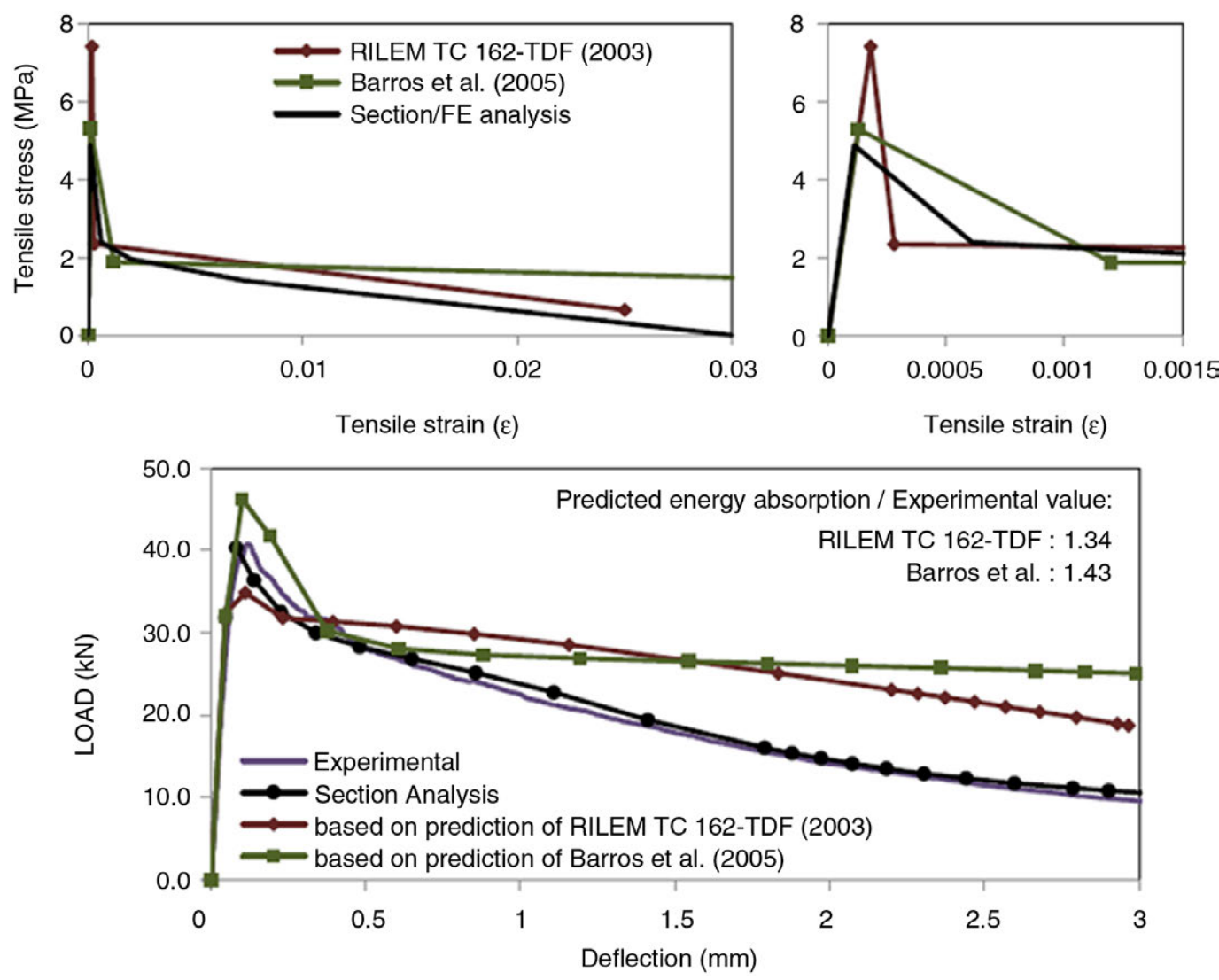

FIGURE 9. RSFRC mix (RCC-C300-R2-90d-N); empirical trilinear estimations compared with section analysis.

These data have been obtained for all the examined mixes and are compared in Table 4.

The comparison shows that:

1. For both SFRC and RSFRC, the trilinear $\sigma-\varepsilon$ simplification is not always leading to good predictions, as in CC-C380-IT2-28d-N for which there is strain hardening after cracking (see Figure 8).

2. For both SFRC and RSFRC, the trilinear approximation by Barros et al. (3) gives a reasonable estimation for the tensile strength but its estimation is not good for the total strain in the strain softening regime. RILEM TC 162TDF (3) gives a weak estimation for the tensile strength, while its total strain estimation is reasonable in most of the cases.

3. The energy absorption is generally overestimated by the empirical methods (except for $\mathrm{RCC}$ reinforced with twincone fibres); in average $27 \%$ (SD 18\%) by RILEM TC 162-TDF (3) and $31 \%$ (SD $25 \%$ ) by Barros et al. (5).

4. The best prediction was obtained for SFRC (CC and RCC) reinforced with hooked-end fibres, by up to $18 \%$ overestimation of the energy absorption.
5. For CC mixes reinforced with twincone fibres and recycled fibres, this overestimation is in the range of $40-63 \%$.

6. For RCC reinforced with higher percentages of fibres $(4 \%$ and $6 \%)$, the prediction of the energy absorption is more reasonable (by around $20 \%$ overestimation).

7. The empirical methods have the same accuracy when adopted for the notched and the unnotched test results.

\subsection{Modified multilinear relationship}

For the examined mixes in this study, the following equations have been statistically calibrated to the experimental load-deflection results to directly determine the multilinear $\sigma-\varepsilon$ relationship. The following equations can reasonably cover the behaviour of CC and RCC reinforced with IF or RF [3].

$$
\begin{array}{lll}
\sigma_{1}=0.42 f_{c t m, f l}(1.6-d) ; & \sigma_{2}=0.5 k_{h} f_{R, 1} ; & \sigma_{3}=0.50 k_{h} f_{R, 2} \\
\mathcal{E}_{1}=\sigma_{1} / E_{c} ; & \varepsilon_{2}=0.5 \% ; & \varepsilon_{3}=2.5 \% ;
\end{array}
$$


TABLE 4. Summary of the results

\begin{tabular}{|c|c|c|c|c|c|c|c|c|}
\hline \multirow[b]{2}{*}{ Mix code } & \multicolumn{4}{|c|}{$\begin{array}{c}\text { Overestimation in the predicted } \\
\text { energy absorption }\end{array}$} & \multicolumn{4}{|c|}{$\begin{array}{l}\text { Predicted tensile strength, normalized to the } \\
\text { predicted value by SA* }\end{array}$} \\
\hline & RILEM & Barros & SA & MMR** & RILEM & Barros & SA & MMR \\
\hline CC-C380-IH2-28d-N & $18 \%$ & $11 \%$ & $2 \%$ & $7 \%$ & 1.5 & 1.1 & 1.0 & 0.9 \\
\hline CC-C380-IT2-28d-N & $55 \%$ & $61 \%$ & $3 \%$ & $-3 \%$ & 2.1 & 1.5 & 1.0 & 1.3 \\
\hline CC-C380-R2-90d-N & $49 \%$ & $60 \%$ & $-2 \%$ & $-2 \%$ & 1.4 & 1.0 & 1.0 & 0.9 \\
\hline CC-C380-R2-90d-UN & $40 \%$ & $63 \%$ & $5 \%$ & $-8 \%$ & 1.5 & 1.0 & 1.0 & 0.9 \\
\hline RCC-C300-IH2-28d-N & $11 \%$ & $2 \%$ & $-4 \%$ & $7 \%$ & 1.8 & 1.3 & 1.0 & 1.1 \\
\hline RCC-C300-IT2-28d-N & $-7 \%$ & $-12 \%$ & $1 \%$ & $14 \%$ & 1.6 & 1.1 & 1.0 & 0.9 \\
\hline RCC-C300-R2-90d-N & $34 \%$ & $43 \%$ & $3 \%$ & $2 \%$ & 1.5 & 1.1 & 1.0 & 1.0 \\
\hline RCC-C300-R2-90d-UN & $28 \%$ & $45 \%$ & $3 \%$ & $-7 \%$ & 1.4 & 1.0 & 1.0 & 0.9 \\
\hline RCC-C300-R4-28d-N & $21 \%$ & $19 \%$ & $-1 \%$ & $4 \%$ & 2.0 & 1.5 & 1.0 & 1.2 \\
\hline RCC-C300-R6-28d-N & $20 \%$ & $18 \%$ & $1 \%$ & $2 \%$ & 1.9 & 1.3 & 1.0 & 1.1 \\
\hline \multirow[t]{2}{*}{ Average (SD) } & $27 \%(18)$ & $31 \%(25)$ & $1 \%(2)$ & $2 \%(6)$ & $1.7(0.2)$ & $1.2(0.2)$ & $1.0(0.0)$ & $1.0(0.1)$ \\
\hline & \multicolumn{8}{|c|}{$\begin{array}{l}\text { Total strain in the softening regime, normalized to the predicted value by SA } \\
\text { (extrapolated to reach zero stress) }\end{array}$} \\
\hline Mix code & \multicolumn{2}{|c|}{ RILEM } & \multicolumn{2}{|c|}{ Barros } & \multicolumn{2}{|c|}{ SA } & \multicolumn{2}{|c|}{ MMR $^{* *}$} \\
\hline CC-C380-IH2-28d-N & \multicolumn{2}{|c|}{1.5} & \multicolumn{2}{|c|}{5.5} & \multicolumn{2}{|c|}{1.0} & \multicolumn{2}{|c|}{0.8} \\
\hline CC-C380-IT2-28d-N & \multicolumn{2}{|c|}{1.0} & \multicolumn{2}{|c|}{4.0} & \multicolumn{2}{|c|}{1.0} & \multicolumn{2}{|c|}{0.9} \\
\hline CC-C380-R2-90d-N & \multicolumn{2}{|c|}{1.2} & \multicolumn{2}{|c|}{4.9} & \multicolumn{2}{|c|}{1.0} & \multicolumn{2}{|c|}{1.2} \\
\hline CC-C380-R2-90d-UN & \multicolumn{2}{|c|}{1.2} & \multicolumn{2}{|c|}{4.9} & \multicolumn{2}{|c|}{1.0} & \multicolumn{2}{|c|}{1.0} \\
\hline RCC-C300-IH2-28d-N & \multicolumn{2}{|c|}{2.5} & \multicolumn{2}{|c|}{8.8} & \multicolumn{2}{|c|}{1.0} & \multicolumn{2}{|c|}{0.8} \\
\hline RCC-C300-IT2-28d-N & \multicolumn{2}{|c|}{3.0} & \multicolumn{2}{|c|}{11.0} & \multicolumn{2}{|c|}{1.0} & 1.3 & \\
\hline RCC-C300-R2-90d-N & 1.1 & & 4 & & $1 .($ & & 0.9 & \\
\hline RCC-C300-R2-90d-UN & 1.1 & & 4 & & 1.0 & & 0.9 & \\
\hline RCC-C300-R4-28d-N & 1.3 & & 5 & & $1 .($ & & 1.0 & \\
\hline RCC-C300-R6-28d-N & 0.8 & & 3. & & $1 .($ & & 0.6 & \\
\hline Average (SD) & 1.5 & & & 2.3) & & & & (0.2) \\
\hline
\end{tabular}

* Section analysis.

**Modified multilinear relationship proposed in this paper.

Where, residual flexural tensile strength parameters, $f_{R j}(\mathrm{j}=1,2,3,4)$, are defined as a fictitious maximum tensile stress with linear stress distribution in an uncracked mid-span section of a prism subjected to a load $P_{j}$ corresponding to deflection $\delta_{j}$ $\left(\delta_{1}=0.5 \mathrm{~mm}, \delta_{2}=1.3 \mathrm{~mm}, \delta_{3}=2.2 \mathrm{~mm}, \delta_{4}=3.0 \mathrm{~mm}\right)$; $f_{R j}=P_{j} l / b h^{2}$. Linear extrapolation is applied to strain values bigger than $20 \%$.

Using this multilinear $\sigma-\varepsilon$ relationship the energy absorption is only overestimated by $2 \%$ (SD 6\%) on average; the predicted tensile strength and total strain in the softening regime are also predicted extremely well (see Table 4).

It should be noted that the proposed relationship is based on experiments conducted on smallscale specimens. For real-scale structures, it is recommended to examine satisfactory reproduction of the results by conducting large-scale bending tests.

\section{CONCLUSIONS}

The accuracy of the trilinear empirical estimations suggested by RILEM TC 162-TDF (3) and Barros et al. (5), for obtaining the $\sigma-\varepsilon$ constitutive law from the experimental flexural behaviour of SFRC specimens, was assessed as well as the applicability of these estimations for RSFRC and RCC. Experimental testing and numerical inverse analysis were performed on a series of $\mathrm{CC}$ and $\mathrm{RCC}$ mixes reinforced with IF and RF. For cross-checking purposes, three approaches were used for numerical 
modelling (section analysis, FE concrete smeared crack, and FE concrete damaged plasticity); their results were compared and verified. The following was found:

- For both SFRC and RSFRC, the energy absorption is generally overestimated (sometimes up to $60 \%$ ) by the trilinear empirical methods.

- Barros et al. (5) approximation gives a reasonable estimate of the tensile strength, but its estimate for the total strain in the softening regime is not good.

- $\quad$ RILEM TC 162-TDF (3) approximation gives a weak estimation for the tensile strength, while its total strain estimation is reasonable in most of the cases.

The stiffness of a notched prism can be approximated satisfactorily equal to the stiffness of an unnotched one with the same height as its mid-span.

A modified multilinear $\sigma-\varepsilon$ relationship was proposed in this paper to predict the post-cracking behaviour of steel-fibre-reinforced-concrete, based on the small-scale experimental load-deflection results. This relationship can cover the post-crack behaviour of both $\mathrm{CC}$ and $\mathrm{RCC}$ reinforced with IF or RF, with only $2 \%$ average overestimation in the energy absorption and good prediction of tensile strength and total strain in the softening regime. Examining the accuracy of this relationship for large-scale elements needs further experimental studies.

\section{ACKNOWLEDGEMENTS}

The authors acknowledge the financial support of the 6th Framework Programme of the European Community under contract number 031530.

\section{REFERENCES}

1. ACI 544.4R (1999) Design considerations for steel fibre reinforced concrete. Amer Concr Inst, USA.

2. CEB-FIP Model Code (2010) Design Code for Concrete Structures, Volume 1. International Federation for Structural Concrete (fib), Lausanne.

3. RILEM TC 162-TDF (2003) Test and design methods for steel fibre reinforced concrete, $\sigma-\varepsilon$ design method. Final recommendation. Mater \& Struct. 36 [262], 560-567.

4. Tlemat, H.; Pilakoutas, K.; Neocleous, K. (2007) Modelling of SFRC using inverse finite element analysis. Mater \& Struct. 39, 221-233. http://dx.doi.org/10.1617/ s11527-005-9010-y.

5. Barros, J.A.O.; Cunha, V.M.C.F.; Ribeiro, A.F.; Antunes, J.A.B. (2005) Post-cracking behavior of steel fibre reinforced concrete. Mater \& Struct. 38 [275], 47-56. https:// dx.doi.org/10.1007/BF02480574.

6. Erol Erdem, HOCHTIEF Construction AG, HOCHTIEF Consult (2003) The flexural behaviour of SFRC beams and slabs: Bending with $\sigma-\varepsilon$ method, RILEM TC 162-TDF Workshop, Bochum, Germany.

7. Barros, J.; Antunes, J. (2003) Experimental characterization of the flexural behaviour of steel fibre reinforced concrete according to RILEM TC 162-TDF recommendations, RILEM TC 162-TDF Workshop, Bochum, Germany.

8. Neocleous, K.; Angelakopoulos, H.; Pilakoutas, K.; Guadagnini, M. (2011) Fibre reinforced roller compacted concrete transport pavements. Transport 164 [TR2], 97-109. http://dx.doi.org/10.1680/tran.9.00043.

9. UoS (University of Sheffield) (2005) Thin wire reinforcement for concrete. Br Patent Application No 0130852.7 and 0511012.7, Sheffield, UK.

10. Neocleous, K.; Pilakoutas, K.; Tlemat, H. (2006) Design issues of concrete reinforced with steel fibres recovered from tyres. ASCE J Mate. Civil Eng 18 [5], 677-685. https:// dx.doi.org/10.1061/(ASCE)0899-1561(2006)18:5(677).

11. Ecolanes (EU FP6 STREP project) (2006-2009) Economical and sustainable pavement infrastructure for surface transport. Contract 031530 .

12. Graeff, AG.; Pilakoutas, K.; Neocleous, K.; Vania, M. (2012) Fatigue resistance and cracking mechanism of concrete pavements reinforced with recycled steel fibres recovered from post-consumer tyres. Eng Struct. 45, 385-395. http://dx.doi.org/10.1016/j.engstruct.2012.06.030.

13. Jafarifar, N. (2012) Shrinkage behaviour of steel-fibrereinforced-concrete pavements. PhD thesis, University of Sheffield, UK

14. Jafarifar, N.; Pilakoutas, K.; Bennett, T. (2014) Moisture transport and drying shrinkage properties of steel-fibrereinforced-concrete. Constr Build Mater 73 [2014] 41-50. http://dx.doi.org/10.1016/j.conbuildmat.2014.09.039.

15. Jafarifar, N.; Pilakoutas, K.; Bennett, T. (2015) The effect of shrinkage cracks on the load bearing capacity of steelfibre-reinforced-concrete. Mater and Struct. http://dx.doi. org/10.1617/s11527-015-0652-0.

16. RILEM TC 162-TDF (2002) Test and design methods for steel fiber reinforced concrete. Design of steel fibre reinforced using $\sigma-\varepsilon$ method: principles and applications. Mater.\& Struct. 35 [249] 262-278.

17. BS 8500-1 (2006) Concrete-Complementary British Standard to BS EN 206-1- Part 1: Method of specifying and guidance for the specifier. Br Stand Inst. London.

18. Prisco, M.di; Colombo, M.; Dozio, D. (2013) Fibrereinforced concrete in fib Model Code 2010: principles, models and test validation, Structural Concrete 14 [2013], No. 4.

19. Timoshenko, S.P.; Goodier, J.N. (1970) Theory of elasticity. 3rd Edition, McGraw Hill, New York.

20. BS EN 14651 (2005) Test method for metallic fibered concrete - Measuring the flexural tensile strength. Br Stand Inst, London, UK.

21. JSCE-SF4 (1984) Methods of tests for flexural strength and flexural toughness of steel fibre reinforced concrete. Japan Society of Civil Engineers, Concrete Library.

22. JCI-S-001 (2003) Method of test for fracture energy of concrete by use of notched beam. Japan Concrete Institute Standard.

23. ASTM C 1018 (1997) Standard test method for flexural toughness and first-crack strength of fibre-reinforced concrete (Using beam with third-point loading). American Standards, USA.

24. JCI-S-003 (2007) Method of test for bending momentcurvature curve of fiber-reinforced cementitious composites. Japan Concrete Institute Standard.

25. BS EN 12390-3 (2009) Testing of hardened concrete Part 3: Compressive strength of test specimens. Br Stand Inst, London, UK.

26. Alexander, M.G. (1982) A simple bending test for elastic and rupture moduli for plain concrete and mortar. Concretel Beton, South Africa 92 [27], 18-24.

27. Casanova, P.; Rossi, P. (1997) Analysis and design of steel fibre reinforced concrete beams. ACI Struct J 94 [5], 595-602.

28. ABAQUS Version 6.10 (2010) Dassault Systèmes Simulia Corp., USA.

29. Elshaigh, W.A. (2007) Modelling the behaviour of steel fibre reinforced concrete pavements. PhD thesis, University of Pretoria.

30. Bazant, Z.P.; Oh, B.H. (1983) Crack band theory for fracture of concrete. Mater \& Struct. 16 [3], 155-177. 